\title{
TRANSPOSIÇÃO DIDÁTICA COM APORTE DO GEOGEBRA NA PASSAGEM DA GEOMETRIA PLANA PARA A GEOMETRIA ESPACIAL
}

\author{
DIDACTIC TRANSPOSITION WITH CONTRIBUTION FROM GEOGEBRA IN THE \\ TRANSITION FROM PLANE GEOMETRY TO SPATIAL GEOMETRY
}

\author{
Renata Teófilo de Sousa ${ }^{\mathrm{x}}$ \\ Italândia Ferreira de Azevedo² \\ Francisco Daniel Souza de Lima ${ }^{3}$ \\ Francisco Régis Vieira Alves ${ }^{4}$
}

RESUMO: Este trabalho apresenta uma proposta metodológica para viabilizar a transposição didática no que concerne ao ensino de Geometria Plana e Espacial, tendo em vista a necessidade do conhecimento deste assunto para o Exame Nacional do Ensino Médio (ENEM). O objetivo deste trabalho é apresentar a elaboração de uma sequência didática visando o desenvolvimento da percepção geométrica do aluno no traslado da Geometria Plana para a Espacial com o aporte do software GeoGebra. Para a organização deste trabalho, adotou-se como metodologia uma pesquisa de natureza qualitativa, do tipo exploratória, onde elaborou-se uma sequência didática com vistas a proporcionar uma atividade que desencadeasse a visualização geométrica na passagem da Geometria plana para a Espacial. Concluímos que o GeoGebra forneceu suporte para a trabalhar a visualização e percepção geométrica na sequência didática proposta, o que ressalta sua mais valia para esta pesquisa. Deste modo, espera-se contribuir com o docente de Matemática no que diz respeito à uma abordagem que associa tecnologia, transposição didática e Geometria, com potencial para

\footnotetext{
I ORCID: https://orcid.org/oooo-oooI-5507-2691. Mestranda em Ensino de Ciências e Matemática - IFCE campus Fortaleza. Especialista em Ensino de Matemática - UVA, Qualificação em Ensino de Matemática no Estado do Ceará - UFC. Pós-graduada em Didática e Metodologias Ativas na aprendizagem e MBA em Gestão Escolar - UniAmérica. Professora da Secretaria de Educação Básica do Estado do Ceará - EEEP Professora Lysia Pimentel Gomes Sampaio Sales. E-mail: rtsnaty@gmail.com.

2 ORCID: https://orcid.org/oooo-ooo2-4684-5397. Mestre em Ensino de Matemática pelo Instituto Federal de Ciência e Tecnologia do Estado do Ceará (IFCE). Professora da rede estadual de ensino do Ceará - EEEP Joaquim Moreira de Sousa. E-mail: italandiag@gmail.com.

3 ORCID: https://orcid.org/oooo-ooo3-2575-8857. Mestre em Ensino de Ciências e Matemática - ENCIMA pela Universidade Federal do Ceará - UFC. Professor da Secretaria de Educação Básica do Estado do Ceará (SEDUC-CE). Integrante do grupo de estudo Tecendo Redes Cognitivas de Aprendizagem G-TERCOA, UFC. Professor do curso de GeoGebra na modalidade à distância Universidade Estadual do Paraná. Email: danielufc.souza@gmail.com

4 ORCID: http://orcid.org/oooo-ooo3-3710-156r. Doutor em Educação pela Universidade Federal do Ceará, bolsista de produtividade do CNPQ- PQ2. Professor permanente do Programa de Pós-Graduação em Ensino de Ciências e Matemática do IFCE, Professor permanente do Programa de Pós-Graduação em Ensino de Ciências e Matemática da Universidade Federal do Ceará. Professor permanente do Programa de PósGraduação do Mestrado Profissional em Educação Profissional e Tecnológica. Professor titular do IFCE departamento de Matemática e Física. Coordenador acadêmico do Doutorado em rede RENOEN, polo IFCE. Líder do Grupo de Pesquisa CNPQ Ensino de Ciências e Matemática. Página pessoal: https://ifce.academia.edu/RegisFrancisco/Journal-Articles. E-mail: fregis@ifce.edu.br.
} 
alavancar o raciocínio geométrico do aluno, fazendo jus ao que se busca desenvolver nos currículos escolares.

Palavras-chave: Transposição Didática. Geometria Plana. Geometria Espacial. GeoGebra.

ABSTRACT: This work presents a methodological proposal to make the didactic transposition feasible in what concerns the teaching of Flat and Spatial Geometry, in view of the need for knowledge of this subject for the National High School Examination (ENEM). The objective of this paper is to present the development of a didactic sequence for the development of the geometric perception of students in the transfer of plane geometry to Space with the contribution of GeoGebra software. For the organization of this work, a qualitative research, of the exploratory type was adopted as methodology, where a didactic sequence was elaborated with a view to providing an activity that would trigger the geometric visualization in the transition from flat to spatial geometry. We conclude that GeoGebra provided support for working with geometric visualization and perception in the proposed didactic sequence, which highlights its added value for this research. In this way, it is expected to contribute with the mathematics teacher with respect to an approach that combines technology, didactic transposition and Geometry, with the potential to leverage the student's geometric reasoning, living up to what is sought to develop in school curricula.

Keywords: Didactic Transposition. Plane Geometry.Spatial Geometry. GeoGebra.

\section{INTRODUÇÃO}

Ensinar Geometria tem sido um desafio para os educadores há muito tempo, no que diz respeito à escolha metodológica e, consequentemente a apreensão de conceitos geométricos por parte dos estudantes. De acordo com Nobre (1996) nem sempre o professor tem consciência de que aquele conhecimento por trás do conteúdo a ser ensinado, que aparece de forma pronta nos livros, passou por diversas modificações e aprimoramentos ao longo da história da Matemática, que por sua vez traz toda a fundamentação teórica e as respostas para muitos porquês que permeiam os pensamentos dos estudantes.

As dificuldades no ensino e aprendizagem de Geometria muitas vezes são oriundas de métodos utilizados pelos docentes que não atendem às necessidades dos estudantes, onde docente e estudante enxergam a Geometria de formas distintas, em patamares diferentes. Em alguns casos, a visualização e o traslado da Geometria Plana para a Geometria Espacial, por exemplo, apresentam lacunas. Oliveira e Leivas (2017, p. 109) apontam que "é pertinente trabalhar com situações de aprendizagem que levem o aluno a estabelecer relações entre figuras espaciais e suas representações planas, envolvendo sua observação sob diferentes pontos de vista, construindo e interpretando suas representações”.

Partindo desta premissa, a Base Nacional Comum Curricular (BNCC) (BRASIL, 2018), documento norteador para as diretrizes curriculares na Educação Básica, traz, acerca do ensino de Geometria para o Ensino Médio, que é necessário ao estudante o aprendizado sobre a localização de números em retas, de figuras ou configurações no plano cartesiano e no espaço tridimensional, direção e sentido, ângulos, paralelismo e perpendicularidade, 
transformações geométricas isométricas (que preservam as medidas) e homotéticas (que preservam as formas), bem como sua aplicação em situações-problema.

Conforme Oliveira e Leivas (2017) a Geometria, por seu caráter visual, tem potencial para desenvolver a percepção e autonomia do pensamento e do raciocínio do aluno, desvencilhando-se de estruturas e fórmulas prontas. Tais temas pertencentes ao campo da Geometria, reforçam a necessidade do professor buscar metodologias de trabalho que alcancem a aprendizagem efetiva do aluno.

Com relação ao par Geometria e Tecnologia, a BNCC (BRASIL, 2018) aponta a importância de sua associação para estudo e desenvolvimento do aluno por meio de atividades investigativas com o uso de softwares dinâmicos que inter-relacionem os conceitos geométricos e a realidade, propondo a resolução de problemas como metodologia para que este desenvolvimento ocorra. Deste modo, tem-se que:

[...] o uso de tecnologias possibilita aos estudantes aprofundar sua participação ativa nesse processo de resolução de problemas. São alternativas de experiências variadas e facilitadoras de aprendizagens que reforçam a capacidade de raciocinar logicamente, formular e testar conjecturas, avaliar a validade de raciocínios e construir argumentações. (BRASIL, 2018, p. 528).

Ademais, a resolução de problemas em Geometria é de grande importância para o bom desempenho do estudante em avaliações externas como o Exame Nacional do Ensino Médio (ENEM), por exemplo. As competências e habilidades deste tópico referem-se ao uso do conhecimento geométrico de espaço e forma para realizar a leitura e a interpretação da realidade. Segundo a pesquisa de Alcântara, Sousa e Lima (2015) cerca de 25 a 30\% da prova de Matemática do ENEM envolve conhecimentos geométricos e a necessidade de se explorar esta área do conhecimento deve-se à sua relevância e abordagem no ENEM - que aparece de forma contextualizada, relacionada ao cotidiano - em comparação ao livro didático - com pouca contextualização e exercícios lineares, deixando lacunas na aprendizagem do aluno.

Buscando romper tais dificuldades acerca do ensino de Geometria, o objetivo deste trabalho é apresentar a elaboração de uma sequência didática visando o desenvolvimento da percepção geométrica dos estudantes no traslado da Geometria Plana para a Espacial, utilizando o aporte do software GeoGebra, como suporte ao docente de Matemática, trazendo uma proposta metodológica sobre o assunto.

Sequências didáticas são etapas continuadas de atividades, com um objetivo de ensinar um determinado conteúdo em seu passo a passo, ou como definem Giordan e Massi (2011, apud DOLZ, 2004, p. 97) "uma 'sequência didática' é um conjunto de atividades escolares organizadas, de maneira sistemática". Deste modo, entende-se que para a compreensão da Geometria Espacial, é necessário que antes haja um entendimento da Geometria Plana.

Com relação ao GeoGebra, este foi escolhido por ser um software livre e de fácil manipulação, tendo recursos que exploram a cognição do estudante. Segundo Abar (2020) as metodologias viabilizadas pelo GeoGebra podem dar suporte às estratégias metodológicas do professor, modernizando o saber escolar e transformando este saber em exercícios e problemas capazes de tornar os conceitos mais compreensíveis, visto que o software oferece 
recursos visuais e manipuláveis. Assim, este software oferece possibilidades ao professor de realizar a transposição didática de modo eficaz.

Para que a transposição didática ocorra, segundo Chevallard (199I), é necessária a transformação do saber científico em saber escolar, visto que os objetivos da comunidade acadêmica e da escola são diferentes. Neste sentido, o autor aponta que o saber não chega à sala de aula do mesmo modo que foi produzido no contexto científico, sendo necessária uma "roupagem didática" para que este seja ensinado. Deste modo, trazemos neste trabalho o assunto de Sólidos de Revolução, pautado na proposta de uma sequência didática com vistas a contribuir para que a transposição didática da Geometria ocorra de maneira eficaz, bem como o diálogo entre a Geometria Plana e Espacial.

Nas seções seguintes abordar-se-ão os aspectos históricos, epistemológicos e didáticos acerca do ensino de Geometria, o GeoGebra como recurso para a Transposição Didática, o aprofundamento sobre a metodologia do trabalho juntamente da sequência didática elaborada, bem como as considerações finais dos autores.

\section{Aspectos históricos, epistemológicos e didáticos no ensino de geometria}

Nesta seção serão abordadas de forma sucinta as dimensões histórica, epistemológica e didática no que concerne ao ensino de Geometria na Educação Básica, bem como a aprendizagem do aluno no que diz respeito ao traslado da Geometria Plana para a Geometria Espacial.

\section{I Dimensão Histórica}

Segundo Eves (2004) ao longo dos anos o homem sentiu a necessidade de argumentar logicamente para que certas afirmações quanto ao conhecimento geométrico fossem aceitas como verdade. Assim, surge o que conhecemos por Geometria Demonstrativa, que tem como precursor Tales de Mileto (século VI a.C.), que segundo seus estudos trouxe as primeiras descobertas geométricas para a humanidade.

Outro grande nome dentro da Geometria foi Euclides de Alexandria (300 a.C.), que com sua capacidade de organização sintetizou o que muitos matemáticos precursores a ele desenvolveram, generalizando e demonstrando de forma tão simples e tão clara que gerou sua obra prima "Os Elementos" (BOYER, 1996). Mudanças significativas foram produzidas pelo homem nos mais diversos aspectos da Geometria ao longo dos anos, que nos trazem ao que temos como conhecimento científico hoje.

De algumas décadas para cá a importância da Geometria enquanto componente curricular têm sido enfatizada em diversas pesquisas e valorizada por documentos normativos como os Parâmetros Nacionais Curriculares (PCNs) e, atualmente a Base Nacional Comum Curricular (BNCC), levando em consideração a sua importância para a resolução de problemas ligados à realidade. No entanto, se considerarmos um momento e movimento específicos, oriundo de um passado recente, intitulado de Movimento da Matemática Moderna (MMM), podemos refletir e até compreender algumas das lacunas existentes no processo de ensino e aprendizagem da Geometria na Educação Básica, que ainda deixa seus reflexos até a atualidade. 
Pavanello (1989) aponta que ocorreu um abandono no ensino de Geometria durante o MMM, nas décadas de 6o e 7o, pois os métodos para seu ensino não eram compreendidos e dominados pela maioria dos professores. O foco da Matemática Moderna era trabalhar a Geometria pelo viés das transformações. A Geometria passou a ser desenvolvida intuitivamente, sem qualquer preocupação com a construção de uma sistematização, apenas com uma linguagem simbólica da Teoria dos Conjuntos. Os docentes da época, despreparados, prendiam-se à Álgebra e Aritmética, deixando a Geometria de lado. De acordo com a autora, sobre os livros didáticos da época têm-se:

\footnotetext{
Quanto à Geometria, opta-se, num primeiro momento, por acentuar nesses livros as noções de figura geométrica e de intersecção de figuras como conjuntos de pontos no plano, adotando-se, para a sua representação, a linguagem da teoria dos conjuntos. Procura-se trabalhá-la segundo uma abordagem "intuitiva" que se concretiza, nos livros didáticos, pela utilização dos teoremas como postulados, mediante os quais pode-se resolver alguns problemas. Não existe qualquer preocupação com a construção de uma sistematização a partir das noções primitivas e empiricamente elaboradas. (PAVANELLO, 1993, p. 13).
}

Ainda hoje podemos ver o reflexo desse sistema de ensino em nossos alunos, baseado na formação dos professores, que por sua vez foram formados dessa maneira. Muitos de nossos alunos sabem calcular manualmente, mas, em sua maioria, apresentam dificuldades em executar o mesmo cálculo, caso a situação seja apresentada na forma de um problema contextualizado. Isso é um reflexo da mecanização da Matemática, que vem de muito tempo atrás. Os estudantes precisavam, à época, apenas de boa memória, mas não de raciocínio e compreensão propriamente ditos, o que nos traz a discussão sobre os obstáculos epistemológicos acerca do ensino de Geometria.

\subsection{Dimensão epistemológica}

É comum o uso de métodos para facilitar a aprendizagem da Geometria, como o emprego de analogias, esquemas, imagens, comparações, entre outros, que deveriam, em teoria, auxiliar a construção do conhecimento do aluno. Contudo, na realidade, isso não ocorre de forma adequada - salvo casos em que os conteúdos são bem articulados pelos docentes. Muitas linhas de raciocínio acabam sendo substituídas por esquematizações que podem ser desfavoráveis ao ensino. A partir do momento em que as atividades empíricas que os estudantes vivenciam no seu cotidiano resultam em uma assimilação inadequada, há a formação do que se denominam obstáculos epistemológicos (BACHELARD, 1996).

A Geometria Plana faz parte dos currículos escolares e seus postulados servem como base para a compreensão da Geometria Espacial. Deste modo, há uma relação entre esses dois campos. Alves e Borges Neto (20II) apontam que o sujeito (aluno) se apoia em imagens mentais, vivenciadas no seu dia a dia com base em objetos do mundo físico para compreender a Geometria. Por outro lado, quando este sujeito/aluno passa por algum treinamento formal, espera-se que ele manifeste percepções geométricas como linearidade, regularidade, profundidade das figuras. Com relação à profundidade, esta merece ser destacada, pois, apesar de exibir um viés intuitivo, em geral, no ensino de Geometria Espacial, as representações são exibidas no plano, transmitindo uma ilusória impressão de pertencimento ao espaço tridimensional. 
Segundo a BNCC (BRASIL, 2018) os estudantes devem encontrar significado nos problemas geométricos, identificando conceitos e elaborando estratégias para sua resolução, considerando a análise de modelos pré-existentes e verificando sua validação para as situações propostas. Na competência específica 3, da área de Matemática e suas tecnologias, a BNCC traz que:

Utilizar estratégias, conceitos e procedimentos matemáticos, em seus campos Aritmética, Álgebra, Grandezas e Medidas, Geometria, Probabilidade e Estatística -, para interpretar, construir modelos e resolver problemas em diversos contextos, analisando a plausibilidade dos resultados e a adequação das soluções propostas, de modo a construir argumentação consistente. (BRASIL, 2018, p. 527).

Deste modo, a Geometria - plana, espacial e analítica -, conforme a BNCC, é um campo que fornece meios para resolver problemas ligados à realidade e que explora o desenvolvimento do pensamento geométrico, trabalhando com formas, relacionando figuras planas e espaciais e até mesmo a relação entre a Álgebra e a Geometria, dada a necessidade do homem de se encontrar dentro do espaço.

Entretanto, mesmo com sua relevância comprovada, a Geometria enquanto componente curricular é ainda um entrave para os estudantes. Há uma ruptura na transição da Geometria Plana para a Geometria Espacial, existindo maior dificuldade na percepção e associação dos entes geométricos fundamentais e sua respectiva associação à composição de figuras espaciais. Para Lorenzato (1995, p. 3) "muitos professores não detêm os conhecimentos geométricos necessários para realização de suas práticas pedagógicas".

Segundo Camilo, Alves e Fontenele (2020) há certa rejeição por parte dos estudantes a este componente curricular, possivelmente devido à dificuldade que os professores de Matemática enfrentam em apresentar de forma compreensível a exposição visual, pois em muitas vezes, estes só dispõem de recursos pedagógicos limitados a meios tradicionais.

O ENEM comumente utiliza questões de Geometria em seus testes para explorar potencialidades acerca do raciocínio geométrico dos estudantes. Devido sua aplicabilidade, é um assunto bastante recorrente em suas provas, sendo necessário seu desenvolvimento para que haja um bom desempenho nesta área do conhecimento. Sua Matriz de Referência, com relação à temática em questão, apresenta como competências e habilidades:

\footnotetext{
Competência de área 2 - Utilizar o conhecimento geométrico para realizar a leitura e a representação da realidade e agir sobre ela.

H6 - Interpretar a localização e a movimentação de pessoas/objetos no espaço tridimensional e sua representação no espaço bidimensional.

$\mathrm{H}_{7}$ - Identificar características de figuras planas ou espaciais.

H8 - Resolver situação-problema que envolva conhecimentos geométricos de espaço e forma.

H9 - Utilizar conhecimentos geométricos de espaço e forma na seleção de argumentos propostos como solução de problemas do cotidiano. (BRASIL, 2009, p. 5)
}

O que se pode notar é que há um alinhamento entre a BNCC e a Matriz de Referência do ENEM no que diz respeito à Geometria enquanto componente curricular. Ambas as matrizes ressaltam a importância da associação do pensamento geométrico à realidade e reforçam a questão da construção de modelos para a solução de problemas. 
Partindo de tais premissas, a sequência didática a ser apresentada neste trabalho traz o viés que articula essa passagem da Geometria Plana para a Espacial, no tópico de Sólidos de Revolução. Para tal, o amparo do GeoGebra enquanto recurso tecnológico viabiliza a percepção visual e a compreensão de conceitos geométricos.

\subsection{Dimensão didática}

Diversos autores têm desenvolvido pesquisas ao longo dos anos quanto ao ensino de Geometria na educação básica, visando fornecer subsídios para os docentes no intuito de melhorar a compreensão deste componente curricular. Alguns autores são apontados nesta pesquisa, como Pavanello (2004), Machado (2010) e Souza Júnior, Cardoso e Calixto (2014).

Para Pavanello (2004) as habilidades de percepção do espaço tridimensional, a orientação e a localização no espaço, a capacidade de observação de objetos não têm sido trabalhadas de forma efetiva ao longo dos anos na educação básica, reforçando a importância de traçar estratégias para que tais habilidades sejam desenvolvidas.

Machado (2010) aponta em sua pesquisa que muitas das dificuldades dos alunos em Geometria Espacial são decorrentes de entraves no que tange à Geometria Plana, não havendo um diálogo entre estes dois campos, sendo estes trabalhados de forma desvinculada, desconsiderando a simbiose entre eles.

Souza Júnior, Cardoso e Calixto (2014) trazem que a representação de objetos tridimensionais no plano bidimensional é um dos obstáculos epistemológicos que impedem a compreensão da Geometria Espacial pelos estudantes, sendo uma dificuldade para muitos professores de Matemática. A figura esboçada no papel ou no quadro não corresponde à sua forma original, dificultando o desenvolvimento da imagem mental do objeto e inviabilizando a visualização e apreensão do conhecimento, o que reforça a necessidade de desenvolver essa percepção no estudante.

Sobre a análise das dimensões didática e epistemológica, Alves e Cavalcante (2017) trazem que os obstáculos devem ser levados em consideração, pois são elementos capazes de impedir o avanço ou até mesmo o processo de compreensão de um estudante que foi submetido a uma ação de ensino intencional. Nesse sentido, argumenta-se a importância da construção do pensamento geométrico de forma coerente. Para tal, aponta-se neste trabalho o software GeoGebra como recurso facilitador da aprendizagem e de percepção geométrica, sendo elemento de grande valia para a transposição didática no traslado da Geometria Plana para a Espacial, como apresentamos na próxima seção.

\section{O GeoGebra como recurso para a Transposição Didática}

O estudo e conceituação de transposição didática está inserido em um campo maior, que é a Didática da Matemática. Chevallard (199I) pondera que a Transposição Didática faz a passagem do saber científico para o saber a ser ensinado, bem como com que roupagem este saber deve chegar à sala de aula. Nesse processo, o professor enquanto mediador realiza o que Chevallard (1991) denomina como trabalho interno de transposição.

No que diz respeito ao contexto de transformação do saber científico para saber a ser ensinado é essencial conferir atenção aos aspectos epistemológicos - com relação ao docente 
- e aos conhecimentos prévios e hipóteses - que concernem ao aluno - para que esta adaptação tenha efeito positivo. Arsac (1992) em consonância a Chevallard (1991) aponta:

A teoria da transposição didática destaca dois pontos fundamentais:

- o problema da legitimação de conteúdos educacionais.

- o aparecimento sistemático de um fosso entre os saberes ensinados e as referências que os legitimam, um fosso devido aos constrangimentos que pesam sobre o funcionamento do sistema educativo. (ARSAC, 1992, p. ı. Tradução nossa).

O que Arsac (1992) denomina como "fosso" são as lacunas de conteúdo préexistentes, que passam de uma série para a outra. Para que tais lacunas sejam minimizadas é necessária uma busca por metodologias que tragam significado para o aluno, consolidando o conhecimento em sua mente e relacionando temas afins entre si.

Vergnaud et al. (1983) explana isso de forma clara ao apontar que uma experiência didática é articulada em torno de uma intenção de ensino. Isso se reflete em particular no fato de que não está apenas interessada em analisar as concepções dos alunos, mas também a sua evolução, em relação às situações propostas e os problemas a resolver. Assim, em busca dessa evolução, no processo de transposição didática o professor é o principal responsável pela transformação do saber para o aluno, trazendo seus aspectos particulares e subjetivos, tornando-o um saber ensinável. No que concerne à essa transformação, aponta-se o GeoGebra como recurso para tal.

O software GeoGebra é um recurso de fácil manuseio, dinâmico e interativo, com potencial para auxiliar a visualização e estruturação de percepções geométricas. Pois, segundo Alves e Borges Neto (2012) a exploração do GeoGebra como instrumento tecnológico possibilita a visualização de situações inimagináveis, quando restritas ao lápis e papel. Já para Scalabrin e Mussato (2020) ao manusear um objeto construído no GeoGebra $3 \mathrm{D}$, as representações das possibilidades de posição deste objeto dentro do ambiente do software proporciona significado e movimento às imagens mentais que são criadas pelo aluno.

Entretanto, Vorpagel et al. (202I) complementa que o simples fato de usar uma ferramenta tecnológica em sala de aula como complemento ao currículo, sem que se tenha um bom planejamento e um objetivo claro a ser atingido pode tornar a própria ferramenta dispensável e, caso seu uso seja distorcido, não desenvolverá uma aprendizagem eficiente no aluno. Assim, é necessário um preparo por parte do docente para realizar uma aula com tais recursos, realizando uma transposição didática eficaz.

A transposição didática por meio de tecnologias já vem sendo estudada por diversos autores da área da Matemática, sendo alguns deles: Silva e Abar (2016), Díaz-Urdanetta, Kalinke e Motta (2019), Abar (2020a; 2020b). Silva e Abar (2016) trazem que a construção de atividades com o GeoGebra possibilita uma modernização do saber escolar, pois o software oferece recursos visuais e manipuláveis, com potencial para facilitar o processo de ensino e aprendizagem.

Díaz-Urdanetta, Kalinke e Motta (2019) reforçam que o GeoGebra é uma ferramenta de matemática dinâmica e por sua acessibilidade e pouca complexidade no uso de suas ferramentas torna-se um recurso que permite uma abordagem diferenciada, possibilitando a apresentação de vários tópicos de Matemática em uma única interface, permitindo uma 
experimentação e visualização da Matemática com grande potencial para desenvolver o conhecimento do aluno.

O GeoGebra é um recurso que facilita a prática do docente, principalmente na apresentação de conteúdos de complexa assimilação. No entanto, muitos professores ainda têm dificuldades em seu manuseio. Uma justificativa para isso, segundo Abar (2020a), é que para elaborar estratégias inovadoras por parte do professor exige uma dedicação maior ao seu desenvolvimento profissional, demandando mais tempo para que este consiga absorver todas as informações, estudar, analisar e transpor todas essas ideias para a sua prática.

Vale salientar que os recursos computacionais devem ser explorados no âmbito escolar de forma mais ativa e com maior frequência para que acompanhem a evolução tecnológica da sociedade. Partindo dessa ótica, Abar (2020a, p 33) enfatiza que "o desenvolvimento das tecnologias da informação e comunicação, bem como sua introdução nas escolas e nos ambientes de formação, é acompanhado de fenômenos da mesma ordem que os da transposição didática". Ou seja, a compreensão do aluno é facilitada uma vez que o suporte tecnológico tem grande dinamismo, fornecendo subsídios para que a transposição didática ocorra de forma significativa.

Para que o recurso do GeoGebra proporcione uma aprendizagem significativa, sugere-se que o docente esteja ciente da melhor forma de realizar a transposição didática do conteúdo associado a este recurso. Assim, "é importante a compreensão do complexo processo de transformação pelo qual passa a matemática até tornar-se um elemento a ser ensinado" (ABAR, 202ob, p. 2).

No que concerne à Geometria, muitos alunos têm dificuldades em compreender problemas por não ter habilidades de visualização e percepção de representações geométricas. Oliveira e Leivas (2017, p. IIo) afirmam que "a Geometria exige a atividade do olhar com o entendimento de que uma imagem desenhada em um plano é a representação de um objeto tridimensional”. Deste modo, temos um obstáculo a transpor, que diz respeito ao tratamento da articulação entre as dimensões bidimensionais (2D) e tridimensionais (3D), ou seja, a articulação da figura no espaço e sua representação. Isto reforça a importância do GeoGebra enquanto recurso manipulável para a ruptura de tais obstáculos, buscando desenvolver de maneira significativa as habilidades de raciocínio geométrico no aluno.

Para ilustrar uma possibilidade metodológica que trata dessa articulação, a próxima seção apresenta uma sequência didática para o desenvolvimento dessas percepções geométricas por meio da visualização no ambiente do GeoGebra.

\section{Percurso metodológico: uma sequência didática sobre sólidos de revolução}

Para a organização deste trabalho, adotou-se como metodologia uma pesquisa de natureza qualitativa, do tipo exploratória. Segundo Gil (2002), este tipo de pesquisa proporciona uma maior familiaridade com o problema, visando torná-lo mais explícito, bem como construir hipóteses sobre ele, buscando um aprimoramento de ideias, o que propicia o alcance do objetivo deste trabalho. Para tal, elaborou-se uma sequência didática com vistas a proporcionar uma atividade que desencadeasse a visualização geométrica e o traslado da Geometria plana para a Espacial.

A sequência didática estruturada traz três questões que ilustram o diálogo entre a Geometria Plana e a Geometria Espacial ilustrando a passagem de uma figura plana, para 
uma secção meridiana e, por fim, chegando a um sólido de revolução originado da figura plana inicial. Tal sequência é composta por: questão I - aponta uma situação em que é necessário o uso de áreas de figuras planas; questão 2 - faz referência à áreas, mas trazendo uma abordagem voltada para o conceito de secção meridiana; questão 3 - ilustra a concepção de sólido de revolução, com base no exposto nas questões anteriores e traz também uma abordagem sobre o cálculo de sua área total.

A resolução das questões está estruturada com o aporte do software GeoGebra e estas são contextualizadas a partir de uma situação real, com base nas competências e habilidades presentes na Matriz de Referência do ENEM, bem como no modelo de questões desta prova.

\section{4.r Questão I: Geometria Plana - o cálculo de uma área}

Portas giratórias são comuns em muitos edifícios como hotéis e agências bancárias, por exemplo. Estas portas têm por finalidade controlar o tráfego de pessoas, manter a segurança do ambiente, monitorar a entrada de pessoas com objetos metálicos - uma vez que nessas portas são instalados sensores - e sua função se estende até mesmo em ajudar no controle da temperatura ambiente. As portas giratórias mais comuns consistem em tampos de vidro com formato retangular chamados de painéis, conhecidos popularmente por "asas". Comumente estas portas possuem duas, três ou quatro asas, que giram sobre um eixo central, como apresenta-se na Figura I(a).

Figura I - Modelo de porta giratória

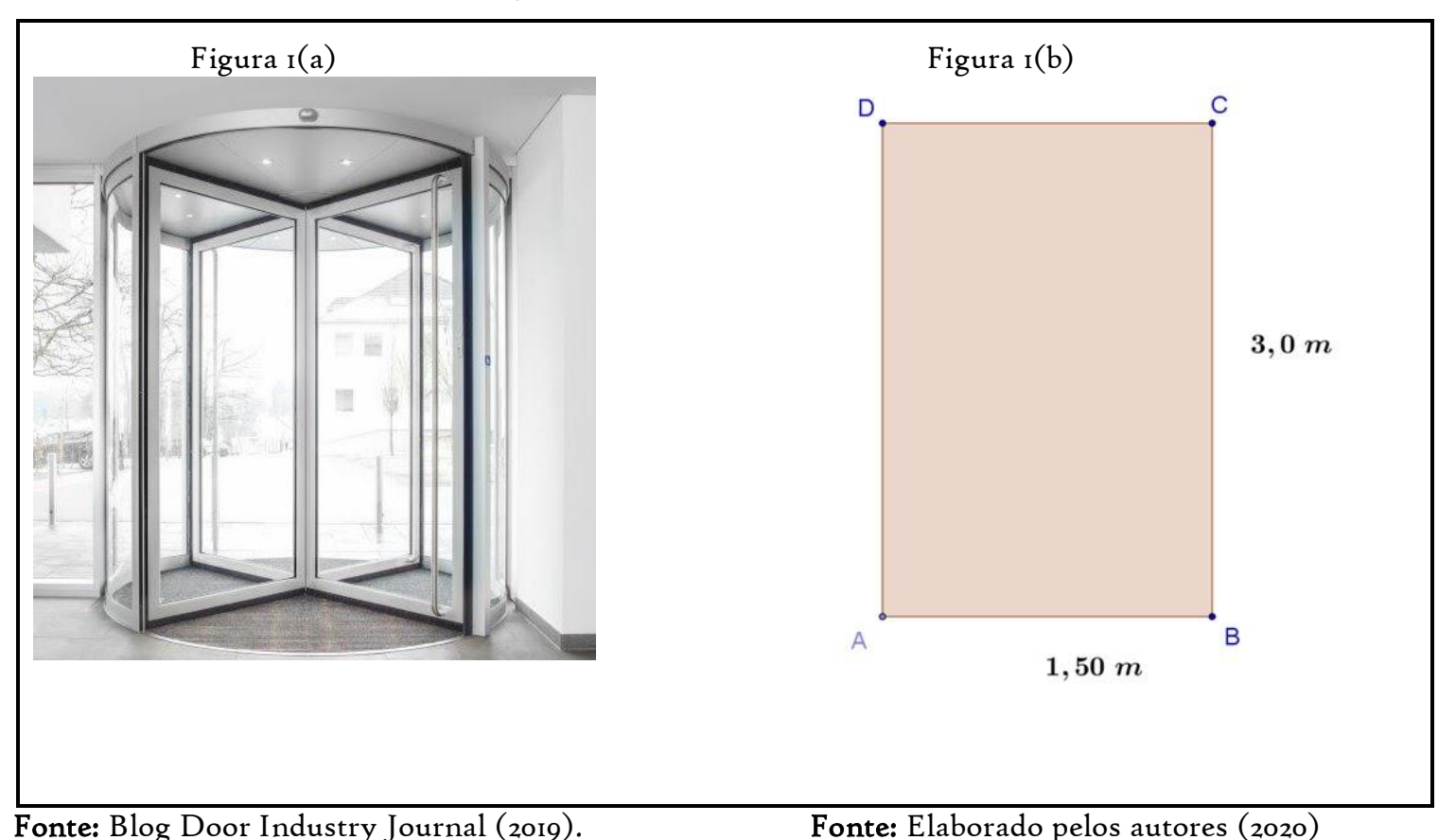

Considerando o painel ou "asa" um dos elementos da porta giratória como um retângulo, temos uma reprodução desta na Figura $\mathrm{I}(\mathrm{b})$, de dimensões reais apontadas. Com base em tais medidas, determine a área do vidro necessário para compor uma destas asas. 
Solução: Nesta questão, busca-se fazer uma analogia entre a Geometria Plana e uma situação real, que é o cálculo da área do vidro necessário para a composição da asa de uma porta giratória. Deste modo, uma possível exploração por meio da construção no GeoGebra, está explanada na Figura 2.

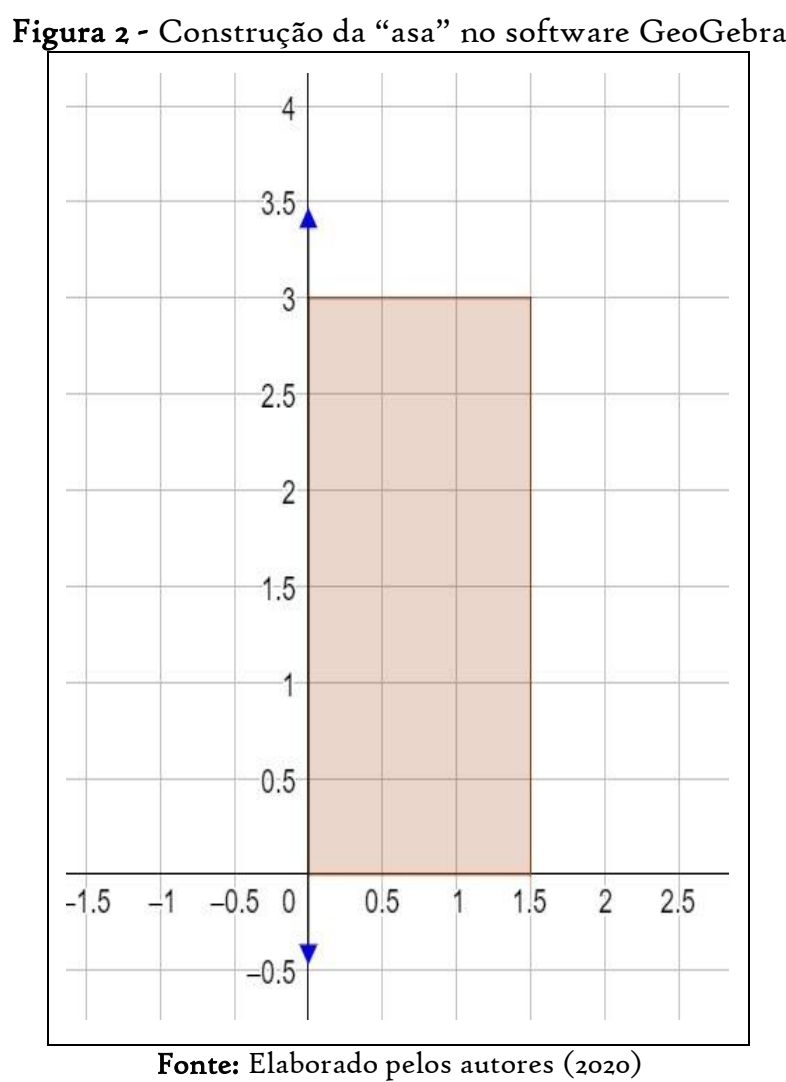

O professor ao apresentar o desenho da "asa" na malha quadriculada, possibilita ao estudante uma visualização de elementos na figura, como as medidas da base e da altura, conseguindo relacionar tais valores ao conceito matemático de área. Desta forma é possível uma contagem da quantidade de quadradinhos da malha quadriculada, onde cada um desses quadradinhos têm medidas $0,5 \mathrm{~m} \times 0,5 \mathrm{~m}$. Para a área da asa, teríamos: $A=0,5 \times 0,5=$ $0,25 \mathrm{~m}^{2}$ para um único quadradinho e $A=0,25 \times 18$ quadradinhos, o que corresponde a $A=4,5 \mathrm{~m}^{2}$. De forma análoga, pode-se apresentar a forma prática para o cálculo da área de um retângulo, que seria $A=b x h$, onde $b$ representa a base da asa e $h$ representa a altura. Assim, teríamos $A=1,5 \times 3,0=4,5 \mathrm{~m}^{2}$, como resposta final.

Alves e Borges Neto (20II) trazem que ao analisar uma figura construída na tela do computador em um ambiente de Geometria Dinâmica - no caso, utilizou-se o GeoGebra -, o aluno pode manifestar e formular conjecturas, produzidas eminentemente a partir da observação/percepção das propriedades que proporcionem uma maior atenção ao observador, formando intuições conjecturais e construindo o pensamento geométrico, o que não seria tão simples se a construção fosse feita à mão, utilizando apenas lápis e papel. 
Deste modo, a proposta da questão foi atingida, pois há a possibilidade de visualização e formulação de ideias a partir da observação da malha quadriculada com seus respectivos valores, facilitando uma compreensão geral sobre o cálculo da área.

\subsection{Questão 2: o conceito de secção meridiana}

Caso a porta giratória tenha número par de painéis de vidro, ao girá-la dois desses painéis ou "asas" imediatamente refletidos em seu eixo de apoio representarão a interseção da estrutura desta porta com um plano que contém o seu eixo OO', como na Figura 3.

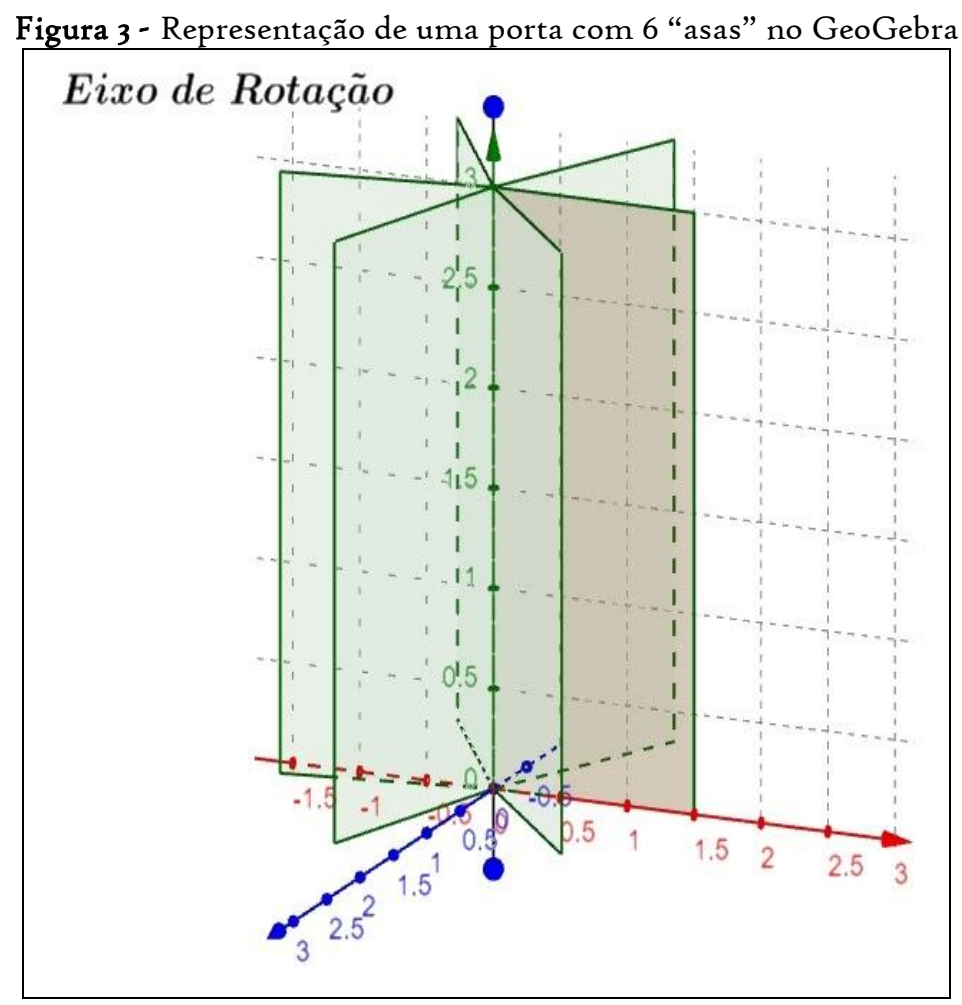

Fonte: Elaborado pelos autores

Assim, considerando que um retângulo maior, composto por duas asas da porta giratória nas condições descritas representa uma secção meridiana desta porta, determine o valor de sua área. Utilize as medidas apresentadas na questão I.

Solução: O professor ao apresentar esta construção no GeoGebra, tem a possibilidade de explicar aos alunos o conceito geométrico de secção meridiana, como sendo uma figura retangular que intersecta a estrutura da porta, no caso, com o eixo central. Assim, o professor pode solicitar aos alunos que considerem quaisquer dois dos retângulos imediatamente refletidos no eixo suporte OO'. Portanto, espera-se que o aluno perceba que o retângulo nestas condições é de tamanho maior, com o dobro do tamanho da base, porém com a mesma altura. Deste modo, a área da secção meridiana pode ser dada por $A=b \times h$, sendo a base $b=3,0$ metros e a altura $h=3,0$ metros. Logo sua área é $A=3,0 \times 3,0=9,0 \mathrm{~m}^{2}$. 
Observe que, ao explorar o GeoGebra, o aluno pode visualizar a secção meridiana como na Figura 4, que traz um destaque para o retângulo formado por duas asas, de medidas $b=3,0 m$ e $h=3,0 m$.

Figura 4 - Visualização da secção meridiana da porta giratória

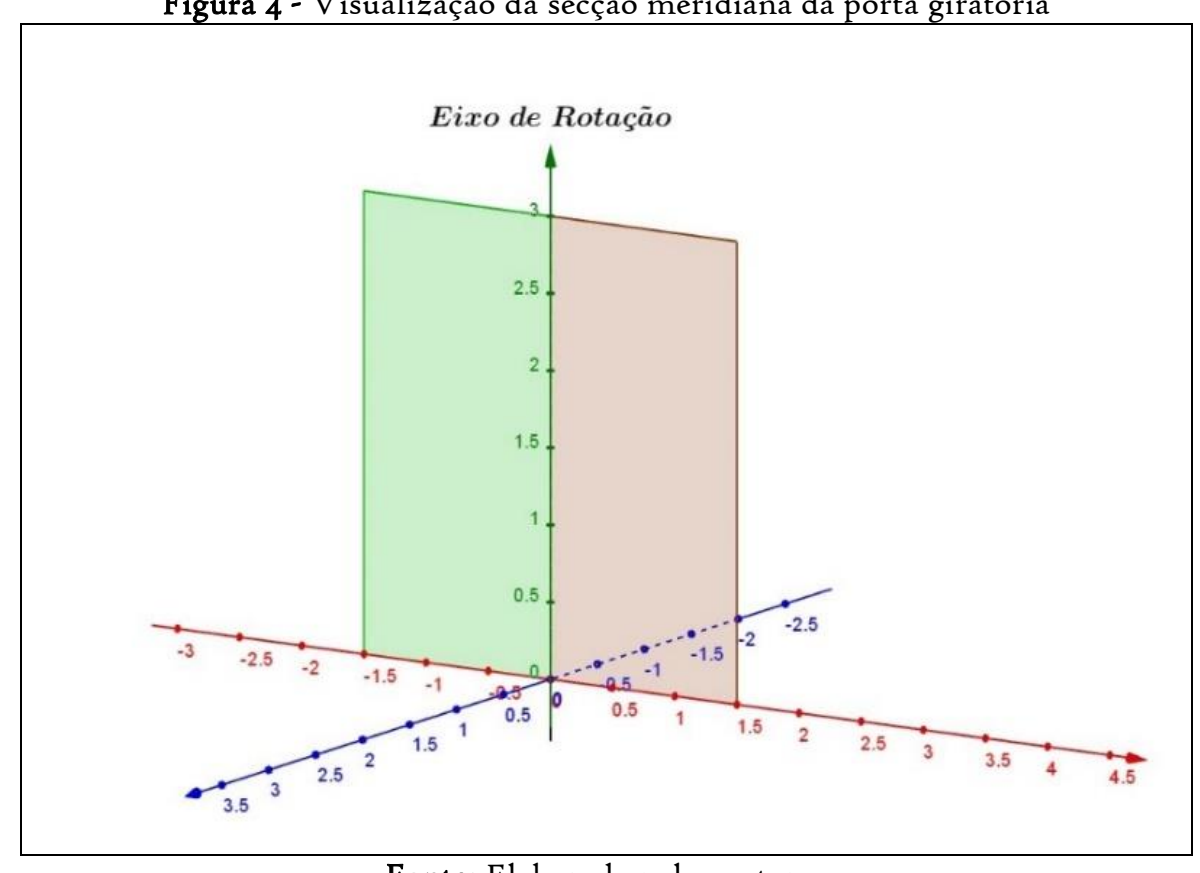

Fonte: Elaborado pelos autores

Vale ressaltar a importância da visualização e percepção dos alunos com o GeoGebra, pois este recurso permite a inferência de informações para além do que a questão apresenta, tornando-se um elemento facilitador do pensamento geométrico. Abar (2020) afirma que o uso do software GeoGebra permite articular saberes a serem ensinados e que não poderiam ser perdidos no decorrer do tempo, corroborando ao pensamento de Chevallard (I99I), onde o conteúdo referente ao saber a ser ensinado, sofre alterações para se adaptar com mais eficiência aos objetivos da educação. Pode-se inferir, a partir deste contexto que o GeoGebra enquanto recurso tecnológico faz essa evolução conceitual a partir do momento em que propicia o diálogo entre a Geometria Plana e Espacial.

\subsection{Questão 3: a percepção geométrica em um sólido de revolução}

Considere que os painéis girem com uma certa velocidade e, a partir de sua rotação, estes preenchem todo o espaço da porta giratória, compondo um sólido de revolução. Utilize as medidas apresentadas na questão I. Nestas condições determine que tipo de sólido de revolução o giro da porta forma no espaço e calcule a área deste sólido.

Solução: A partir das questões i e 2, o professor pode instigar a turma a visualizar e perceber qual o sólido de revolução foi formado pela rotação da porta giratória e espera-se que o aluno conclua que é um cilindro. O professor neste momento pode elucidar o conceito de sólido de revolução, generalizando para outras figuras geométricas. $\mathrm{Na}$ figura 5 , o aluno tem a possibilidade de visualizar que a rotação do retângulo gera um sólido de revolução no formato de um cilindro. 
Figura 5 - Rotação das "asas" em maior velocidade

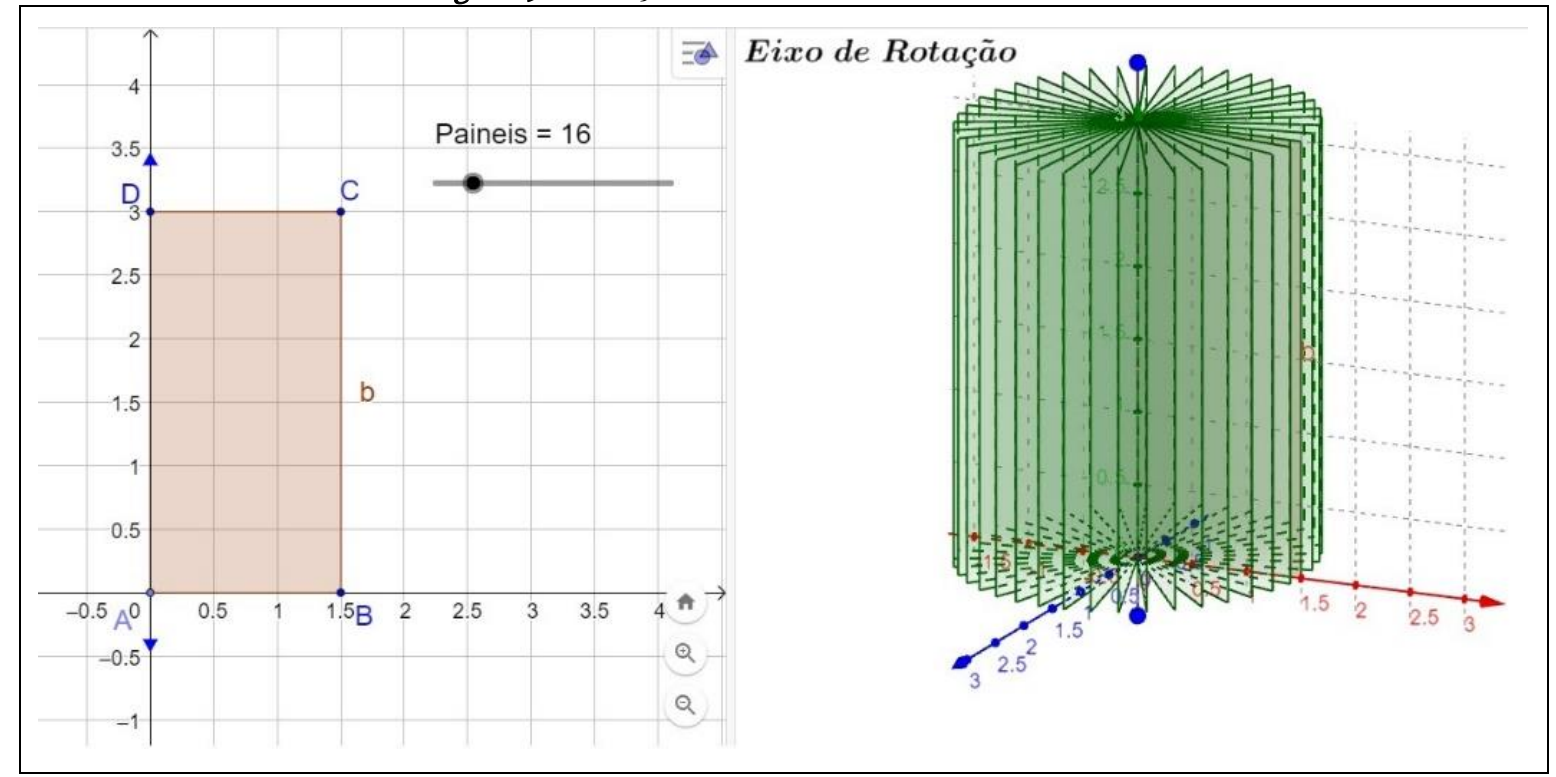

Fonte: Elaborado pelos autores

Dada a Figura 5, constata-se que a construção no GeoGebra fornece suporte visual para que o aluno perceba que a base do retângulo na Figura da esquerda corresponde ao raio da base do cilindro reto, na figura da direita, e sua altura $h=3,0$ metros, permanece a mesma. À medida que o controle deslizante "painéis" aumenta, a quantidade de asas também aumenta, preenchendo o espaço dentro da porta giratória e, consequentemente, formando o cilindro de revolução citado. Para o cálculo da área total, observemos a Figura 6 , que traz o cilindro e sua forma planificada, facilitando a visualização de seus elementos geométricos.

Figura 6 - O cilindro e sua respectiva planificação

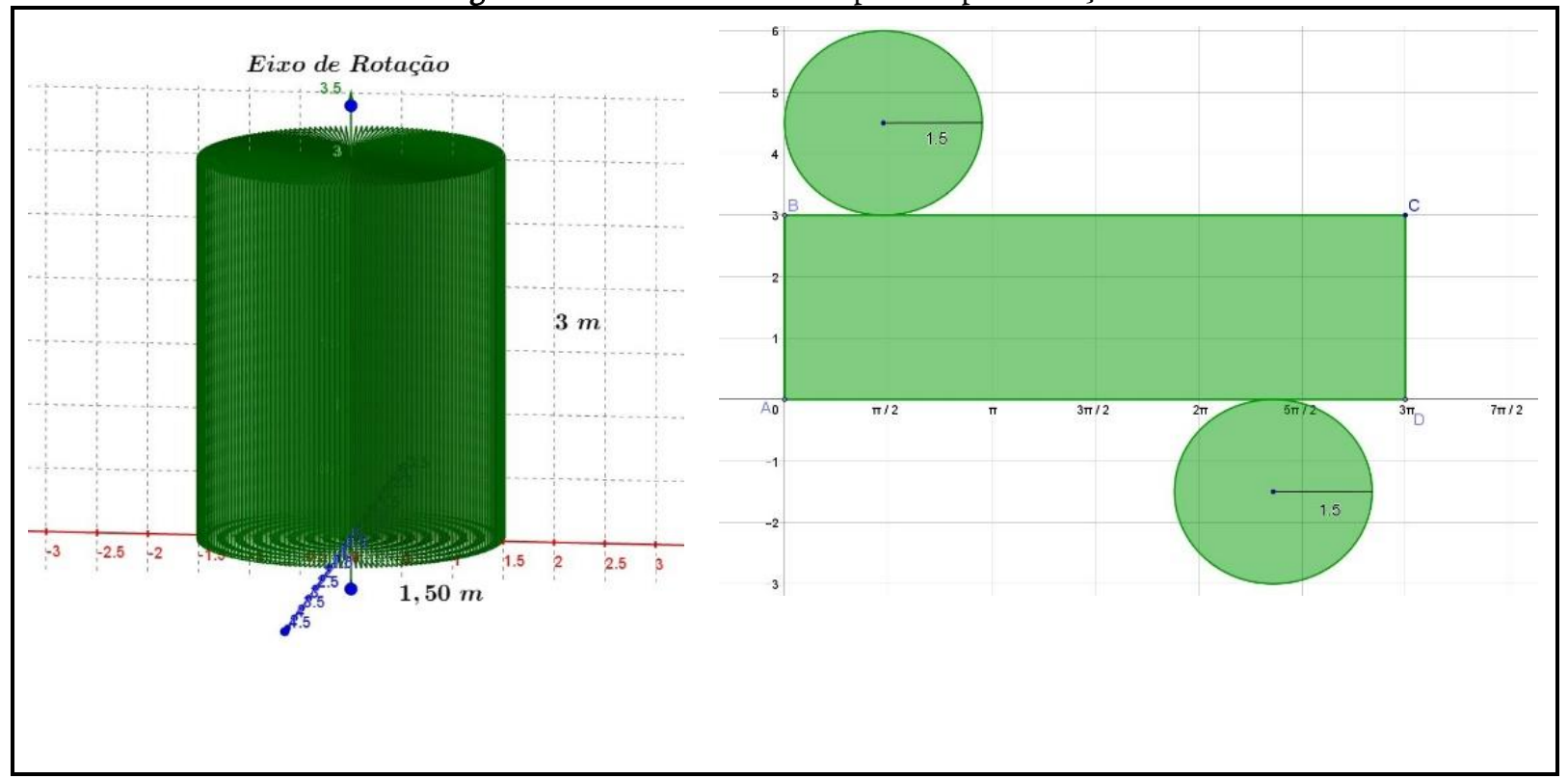

Fonte: Elaborado pelos autores 
Assim, sua área total $\left(A_{t}\right)$ pode ser calculada pelo dobro da área da base $\left(A_{b}\right)$ somada à área lateral $\left(A_{l}\right)$, ou seja, a área de dois círculos de raio $r=1,5 \mathrm{~m}$ e área lateral sendo composta pelo produto do perímetro da circunferência de uma das bases e a altura do cilindro. Caso adote-se o valor 3,14 como aproximação de $\pi$, em linguagem matemática, têm-se:

$$
\begin{gathered}
A_{t}=2 \cdot A_{b}+A_{l} \rightarrow A_{t}=2 \cdot \pi \cdot r^{2}+2 \cdot \pi \cdot r \cdot h \rightarrow A_{t}=2 \cdot \pi \cdot r \cdot(r+h) \\
A_{t}=2 . \pi \cdot 1,5 \cdot(1,5+3)=3,0 \cdot \pi \cdot 4,5 \rightarrow A_{t}=13,5 \cdot \pi \rightarrow A_{t}=13,5 \cdot 3,14 \rightarrow \\
\rightarrow A_{t}=42,39 \mathrm{~m}^{2}
\end{gathered}
$$

Ao recapitular os passos da construção desta sequência didática no GeoGebra, o professor deve enfatizar a importância da visualização geométrica na passagem da Geometria Plana para a Espacial (Figura 7), no que diz respeito à compreensão de que os sólidos espaciais são compostos por figuras planas. Deste modo, para que a transposição didática ocorra, o saber a ser ensinado sofre modificações, os objetos de ensino são convertidos em saberes implementados ao serem modelados com o GeoGebra. Assim, o saber aprendido (aquele que o aluno realmente alcança) decorre da interação do aluno com o dispositivo (ABAR, 202ob).

Figura 7 - Síntese dos passos desta sequência didática no GeoGebra

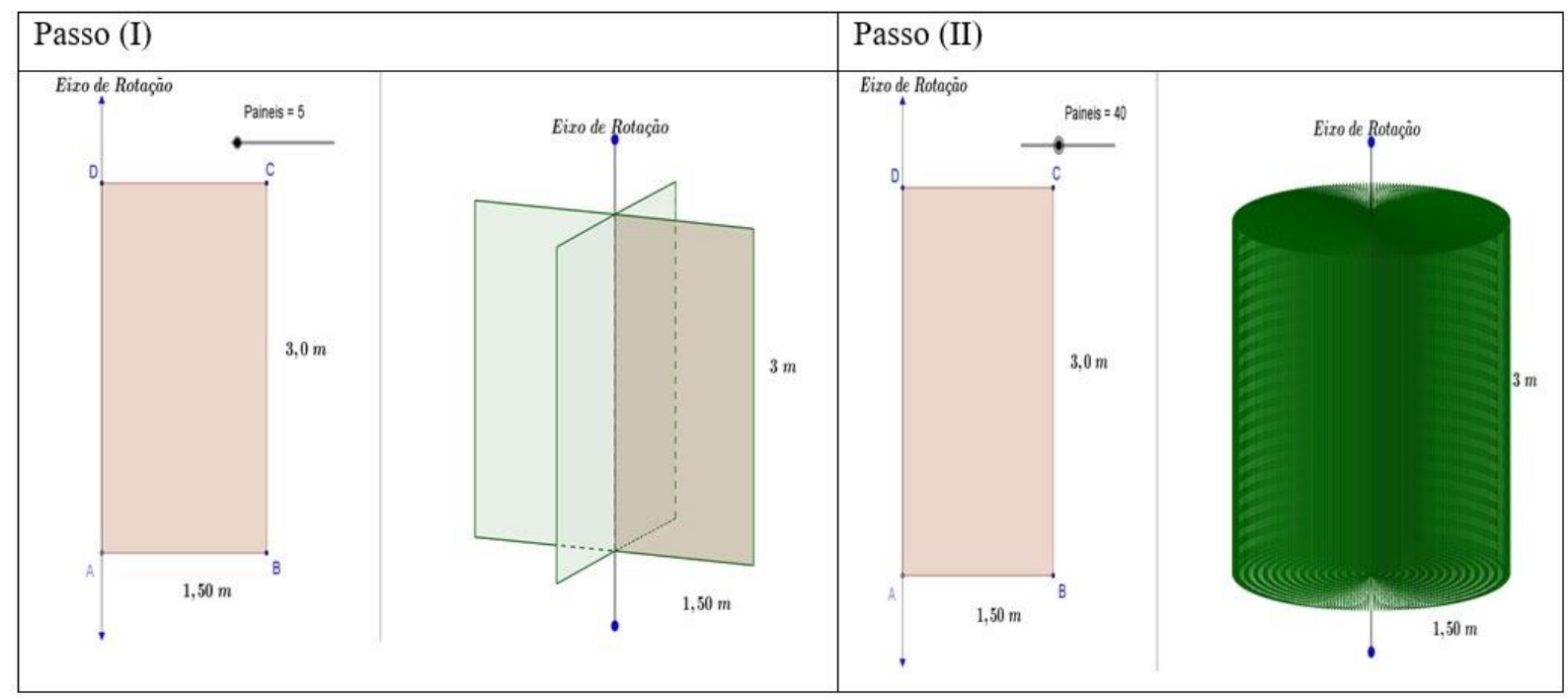

Fonte: Elaborado pelos autores

Ao observar a Figura 7, tem-se que o retângulo construído inicialmente no Passo (I) sofre um processo de transformação geométrica por meio da rotação no eixo suporte, à medida que o controle deslizante "painéis" aumenta seu número. Desta forma, quanto mais painéis, mais a figura do cilindro se torna clara para o aluno. De acordo com Scalabrin e Mussato (2020, p. 439-440) "As potencialidades que o GeoGebra apresenta, com relação aos aspectos visuais, favorece meios para a experimentação com tecnologias". 
Conforme Abar (2020b), o uso de tecnologias digitais no âmbito do saber científico tem potencial para colaborar na compreensão da evolução de um objeto matemático por meio de ideias e conceitos descobertos, que por sua vez evoluíram à medida que foram pesquisados. Neste caso, observa-se a evolução dos objetos matemáticos da seguinte forma: um retângulo (questão I), que por sua vez passa a ser visto como uma secção meridiana de um cilindro (questão 2) e, a partir de sua rotação, gera um cilindro de revolução (questão 3). Em todas as questões solicita-se o cálculo da área, entretanto a visualização e percepção geométrica do aluno é diferente em cada caso e facilitada com o uso do GeoGebra.

Vorpagel et al. (202I) traz que o uso de tecnologias em sala dinamiza as aulas e tem o potencial de promover maior engajamento e participação dos alunos, desenvolvendo a aprendizagem através de atividades de ensino interativas e criativas, consolidando o conhecimento. Nesse sentido, o GeoGebra é um recurso tecnológico que pode desenvolver habilidades visuais, o interesse pela Matemática e o raciocínio geométrico dos alunos, por ser um software de Geometria Dinâmica que permite essa interatividade e a manipulação de suas construções de forma criativa.

\section{Considerações finais}

Com este trabalho conclui-se que esta sequência didática explorada com o software GeoGebra facilita a transposição didática viabilizando o diálogo entre a Geometria Plana e a Geometria Espacial, sendo uma abordagem metodológica valiosa para o professor de Matemática, pois as questões exploradas possibilitam a evolução da percepção geométrica dos alunos, atingindo o objetivo da pesquisa.

A transposição didática do conteúdo de sólidos de revolução pode ser efetiva com o uso do GeoGebra, pois este software, ao permitir visualizações e construções tridimensionais, oportuniza a construção de objetos para experimentação e exploração de conceitos dentro da Geometria Plana e Espacial, como um recurso dinâmico e interativo. Alves e Borges Neto (2012) trazem que a tecnologia pode afetar o processo de mediação no ensino de certos tópicos, no entanto sua utilização em caráter de complementariedade enfatiza uma mudança dimensional, com o objetivo de identificar elementos de natureza qualitativa.

Deste modo, o uso do GeoGebra no viés desta pesquisa traz uma proposta didática relevante para a melhoria da assimilação deste assunto, por meio do desenvolvimento da percepção geométrica do aluno, o que seria bem diferente caso a abordagem ocorresse por métodos tradicionais, restringindo-se ao uso de lápis e papel.

Deparamo-nos com dificuldades em encontrar propostas metodológicas acerca da passagem da Geometria Plana para a Geometria Espacial com viés tecnológico, o que nos mostra a relevância deste assunto no âmbito científico. Portanto sugere-se que o estudo desta área pautado no formato da pesquisa realizada seja difundido, sendo aplicado em sala de aula com vistas a romper barreiras e obstáculos pré-existentes no processo de compreensão deste assunto. Por conseguinte, esta pesquisa pode ser utilizada pelos professores como uma proposta didática para o ensino e a aprendizagem de Geometria. 


\section{REFERÊNCIAS}

ABAR, C. A. A. P. A Transposição Didática na criação de estratégias para a utilização do GeoGebra. Revista do Instituto GeoGebra de São Paulo, v. 9, n. I, p. 59-75, 2020(a). Disponível em: http://dx.doi.org/I0.23925/2237-9657.2020.v9irp59-75. Acesso em: or ago, 2020.

ABAR, C. A. A. P. Teorias da Transposição Didática e Informática na criação de estratégias para a prática do professor com a utilização de tecnologias digitais. Revista Sergipana de Matemática e Educação Matemática, v. 5, n. I, p. 29-45, 2020(b). Disponível em: https://doi.org/ro.34179/revisem.v5ir.I1893. Acesso em: or ago. 2020.

ALCÂNTARA, A. C.; SOUSA, I. S.; LIMA, J. F. L. Geometria no ENEM 2009-2013: a relação com as abordagens no Ensino Médio. Revista Temas em Educação, v. 24, n. 2, p. 4564, 2015. Disponível em: https://periodicos.ufpb.br/index.php/rteo/article/view/21221. Acesso em: 15 nov. 2020.

ALVES, F. R. V.; BORGES NETO, H. A contribuição de Efraim Fischbein para a Educação Matemática e a formação do professor. Conexão, Ciência e Tecnologia, v. 5, n. I, p. 38-54, 201r. Disponível em: https://doi.org/I0.21439/conexoes.v5ir.44I. Acesso em: ro out. 2020.

ALVES, F. R. V.; BORGES NETO, H. Engenharia Didática para a exploração didática da tecnologia no ensino no caso da regra de L'Hospital. Educação Matemática Pesquisa, v. I4, n. 2, p. 337-367, 2012. Disponível em: https://revistas.pucsp.br/index.php/emp/article/view/9445. Acesso em: o5 out 2020.

ALVES, F. R. V.; CAVALCANTE, M. R. Obstáculos (epistemológicos) e o ensino de ciências e matemática. Interfaces da Educação, v. 8, n. 23, p. 253-274, 2017. Disponível em: https://periodicosonline.uems.br/index.php/interfaces/article/view/r6o3. Acesso em: I2 out. 2020.

ARSAC, G. L'évolution d'une théorie en didactique: l'exemple de la transposition didactique. Recherches En Didactique Des Mathématiques, v. 12, n. I, p. 7-32, 1992. Disponível em: https://revue-rdm.com/r992/1-evolution-d-une-theorie-en/. Acesso em: I4 jan. 2021.

BACHELARD, G. A formação do espírito científico: contribuição para uma psicanálise do conhecimento. Rio de Janeiro: Contraponto, 1996.

BOYER, C. B. História da Matemática. São Paulo: Blücher, 1996.

BRASIL. Instituto Nacional de Estudos e Pesquisas Educacionais Anísio Teixeira (INEP). Matriz de referência para o ENEM, 2009. Disponível em: http://download.inep.gov.br/download/enem/matriz_referencia.pdf. Acesso em: io mar. 2020 . 
BRASIL. Base Nacional Comum Curricular, 2018. Disponível em: http://basenacionalcomum.mec.gov.br/. Acesso em:ıo mar. 2020.

CAMilo, A. M. S.; AlVES, F. R. V.; FONTENElE, F. C. F. A Engenharia Didática articulada à Teoria das Situações Didáticas para o ensino da Geometria Espacial. Revista Iberoamericana de Educación Matemática, v. 16, n. 59, p. 64-82, 2020. Disponível em: https://union.fespm.es/index.php/UNION/article/view/r27. Acesso em: io dez. 2020.

CHEVALLARD, Y. La transposition didactique: du savoir savant au savoir enseigné. Paris: Ed. La pensée Sauvage, 1991.

EVES, H. Introdução à história da Matemática. Tradução: Hygino H. Domingues. Campinas: Ed. da Unicamp, 2004.

GIL, A. C. Como elaborar projetos de pesquisa. São Paulo: Atlas, 2002.

GIORDAN, M.; MASSI, M. Uma análise das abordagens investigativas de trabalhos sobre sequências didáticas: tendências no ensino de ciências. Anais... Encontro Nacional de Pesquisa em Educação em Ciências, v. 8, p. I-I3, 20II. Disponível em: http://www.lapeq.fe.usp.br/textos/ec/ecpdf/giordan_guimaraes_massi-enpec-20I2.pdf.

Acesso em: 13 out. 2020.

LORENZATO, S. A. Por que não ensinar Geometria? In: A Educação Matemática em Revista. Blumenau: Sociedade Brasileira de Educação Matemática, v. 4, n. 3, p. 3-13, 1995.

NOBRE, S. (1996). Alguns "porquês” na História da Matemática e suas contribuições para a educação matemática. Cadernos CEDES - História e Educação Matemática. São Paulo: Papirus, v. 40, p. 29-35, 1996.

OLIVEIRA, M. T.; LEIVAS, J. C. P. (2017). Visualização e Representação Geométrica com suporte na Teoria de Van Hiele. Ciência e Natura, v. 39, n. I, p. Io8-117, 2017. Disponível em: https://periodicos.ufsm.br/cienciaenatura/article/viewFile/23170/pdf. Acesso em: ıо out. 2020 .

PAVANELLO, R. M. O abandono do ensino da geometria: uma visão histórica. Dissertação (Mestrado em Educação) - Universidade Estadual de Campinas, Campinas (SP). Disponível em: http://www.repositorio.unicamp.br/handle/REPOSIP/252057. Acesso em: 05 jul. 2020.

PAVANELLO, R. M. O abandono do ensino da geometria no Brasil: causas e consequências. Revista Zetetiké, v. I, n. I, p. 7-17, 1993

PAVANELLO, R. M. (2004). A Geometria nas séries iniciais do ensino fundamental: Contribuições da pesquisa para o trabalho escolar. In: R. M. Pavanello, Matemática nas 
séries iniciais do ensino fundamental: a pesquisa e a sala de aula, v. 2, n. 6, p. 129-I43. São Paulo: Coleção SBEM, 2004.

SCALABRIN, A. M. M. O.; MUSSATO, S. Uso del software GeoGebra: Análisis del proceso de aprendizaje de los conceptos de poliedro. Revista Paradigma, vol. XLI (Extra 2), p. 427-447, 2020. Disponível em: https://doi.org/ro.37618/PARADIGMA.IoII-2251.0.p427447.id922. Acesso em: or mar. 2021.

SILVA, H. N.; ABAR, C. A. A. P. A utilização do GeoGebra na reconstrução de atividades do imagiciel. In: XII Encontro Nacional de Educação Matemática - ENEM, 2or6. Anais... São Paulo, 2016. Disponível em: http://www.sbem.com.br/enem2or6/anais/pdf/6064_2835_ID.pdf. Acesso em: 21 set. 2020.

VERGNAUD, G.; ROUCHIER, A.; DES-MOULIÈRES, S.; LANDRÉ, C.; MARTHE, P.; RICCO, G.; SAMURÇAY, R.; ROGALSKI, J.; VIALA, A. Une expérience didactique sur le concept de volume en classe de cinquième (I2 à 13 ans). Recherches En Didactique Des Mathématiques, v. 4, n. I, p. 71-I20, 1983. Disponível em: https://revue-rdm.com/1983/uneexperience-didactique-sur-le-concept-de-volume-en-classe-de-cinquieme-I2-a-13-ans/.

Acesso em: io fev. 2021.

VORPAGEL, M.; FLORES, S.; ECKERT, B.; RAMOS, D. C.; BARBA, A. N. D. Relato de experiência de Estágio em Matemática no Ensino Médio da rede estadual de educação utilizando o software GeoGebra. Revista Ibero-Americana de Humanidades, Ciências e Educação-REASE, v.7, n. 3, p. 88-96, 2021. Disponível em: https://doi.org/I0.51891/rease.v7i3.760. Acesso em: or mai. 2020. 